\title{
NARCliM model performance including teleconnections with climate modes
}

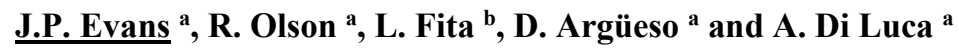 \\ ${ }^{a}$ Climate Change Research Centre and ARC Centre of Excellence for Climate System Science, University of \\ New South Wales, Sydney, NSW, Australia \\ Email:jason.evans@unsw.edu.au \\ ${ }^{b}$ Laboratoire de Météorologie Dynamique, CNR, Université Pierre et Marie curie, Paris,
}

\begin{abstract}
NARCliM (NSW/ACT Regional Climate Modelling project) is a regional climate modelling project for the Australian area. It provides a dynamically downscaled climate dataset for the CORDEXAustralAsia region at $50 \mathrm{~km}$, and South-East Australia at a resolution of $10 \mathrm{~km}$. NARCliM data is being used by the NSW and ACT governments to design their climate change adaptation plans. Data is available through the AdaptNSW website (http://climatechange.environment.nsw.gov.au/).

NARCliM uses version 3.3 of the Weather Research and Forecasting (WRF) regional climate model (RCM) to perform an ensemble of simulations for the present and the projected future climate. WRF is run in three different model configurations (different combinations of physical parametrizations) that have been shown to perform well in the South-East Australia and were chosen based on performance and independence. These three RCMs are used to simulate three different periods: 1990-2009, 2020-2039 and 2060-2079. Four different Global Climate Models (GCMs: MIROC-medres 3.2, ECHAM5, CCCMA 3.1 and CSIRO mk3.0) from CMIP3 are used as initial and boundary conditions for the WRF simulations. These GCMs were chosen through a process that considered model performance, independence and projected future changes. Thus a RCM ensemble of 12 simulations for each period is obtained. Additionally to the GCM-driven simulations, 3 control run simulations driven by the NCEP/NCAR reanalysis for the entire period of 1950-2009 are also performed in order to evaluate the RCMs performance in the area.
\end{abstract}

The NARCliM ensemble is found to have a consistent cold bias throughout the year with many areas showing the ensemble members significantly agreeing on the bias. This bias is significant over most of southeast Australia in winter and summer. The ensemble also displays a consistent wet bias with most of southeast Australia showing significant agreement amongst ensemble members on this bias in summer and autumn. A dry bias is present on the southeast coast in winter

The regional models are found to do a reasonably good job at capturing the teleconnections with large scale climate modes such as El Niño - Southern Oscillation (ENSO), when compared to the driving global data. Each regional model displays differing strengths and weaknesses in this respect.

Keywords: Regional Climate Model, Future Climate Projections, south-east Australia, precipitation, temperature, WRF 


\section{INTRODUCTION}

Future climate change has been recognised as one of the largest issues facing the world in the coming century. The Intergovernmental Panel on Climate Change (IPCC) has been tasked with compiling the state of knowledge in relation to climate change on a regular basis. These assessments are the basis of knowledge used by most governments to establish climate change related policy including the ongoing debates around the introduction of a price on greenhouse gas pollution.

Global Climate Models (GCMs) are the main tools used to project the extent of future climate change. The Coupled Model Intercomparison Project 3 (CMIP3, Meehl et al., 2007) was the international collaborative effort of GCM groups to produce projections that directly informed the IPCC fourth assessment report (IPCC, 2007). This database of global climate projections has been widely used to investigate global climate system processes as well as large scale climate change projections (Marriotti et al., 2008; Evans, 2009a; Vavrus et al., 2009; Evans 2010). This construction of a many GCM ensemble is vital for dealing with the uncertainty associated with future projections. Every GCM, that performs adequately for the recent past, is considered to provide a plausible projection of future climate and it is difficult to know which of these plausible futures is more likely. Hence the use of a multi-model ensemble is required to provide some measure of likelihood of the projected future climate.

As the risks associated with large scale climate change have become better understood, more impact and adaptation studies have been performed. A considerable spatial scale problem exists between the scale of the GCMs (200-400km) and the scales of interest for impacts and adaptation studies which are often only tens of kilometres or less. In order to address this spatial scale problem various methods to downscale the GCM output have been developed. These downscaling methods can be generalised into two types: statistical and dynamical. Statistical downscaling involves deriving statistical relationships between some large scale predictors and the local variable of interest. It is then assumed that this statistical relationship remains true in a future changed climate and hence can be used to downscale both the present and the future climate. Dynamical downscaling uses mathematical representations of the physical processes that create the climate system, similar to GCMs, applied at a higher spatial resolution than the GCMs. In this way they are able to capture climate phenomena not resolved by the GCMs including the influence of mountains and coastlines and local land-atmosphere feedbacks (Zaitchik et al., 2007a,b). Dynamical downscaling is done with a Regional Climate Model (RCM). When downscaling future climate projections RCMs assume that the physical laws remain the same. Statistical downscaling techniques can also be applied to RCM output in order to provide information at point locations.

One advantage of statistical techniques is that they are less computationally intensive and hence can be used to downscale many GCM (or RCM) climate projections. This allows the statistical techniques to be applied to many climate models and hence they can span the range of plausible future climates. RCMs on the other hand, are quite computationally intensive and to date this has prevented them from being used to downscale many GCMs, hence they have not sampled the full range of plausible future climates. This issue has been addressed in a number of large international projects focused on Europe (PRUDENCE - Christensen and Christensen (2007), ENSEMBLES - van der Linden and Mitchell (2009)) and North America (NARCCAP Mearns et al. (2009)) that produced large ensembles of RCM simulations. PRUDENCE was the first attempt to produce a RCM ensemble through a large cooperative international program. In this case several RCMs were used to downscale the same GCM thus providing a measure of the uncertainty associated with RCM simulations but not placing this within the context of plausible future climates simulated by GCMs (Deque et al., 2005). Both ENSEMBLES in Europe and NARCCAP in North America, have attempted to address this issue by using a collection of RCMs to downscale a collection of GCMs. While these projects have found significant spread amongst the RCMs it has generally been smaller than the spread found in the full GCM ensemble (Fowler et al., 2007). Thus, an emphasis on sampling the GCM ensemble more comprehensively has been recommended (Kendon et al., 2010).

Regional benchmark statistics include both general comparisons of observed and modelled variables, as well as metrics aimed at particular phenomena such as the onset and evolution of the monsoon. Many studies have looked at various aspects of the climate system to evaluate RCMs, often with a focus on temperature and precipitation as these are the best observed climate variables. For example, Evans et al. (2005) investigated the performance through time of many variables but only for a single grid point. Kostopoulou et al. (2009) looked at maximum and minimum temperature on a seasonal basis. Evans et al. (2004) and Evans (2009) used temperature and precipitation on climatological and monthly time scales. Solman et al. (2008) looked at seasonal means and cycles, inter-annual variability and extreme events in precipitation and surface air temperatures. Evans and McCabe (2010) evaluated a RCM against precipitation and temperature at daily, monthly, inter-annual and multi-annual time scales including the representation of El Niño - Southern 
Figure 1. AustralAsia domain and topography. The red rectangle outlines the high resolution south-east Australia NARCliM domain.

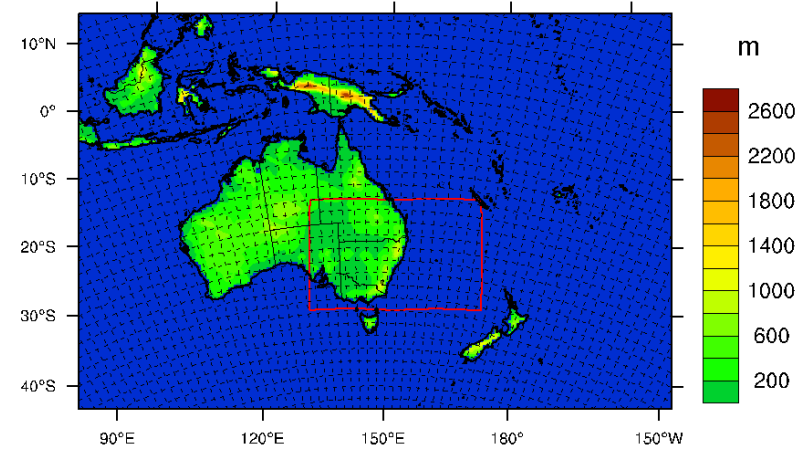

Oscillation (ENSO) and the impact of drought. In addition Argüeso et al. (2012) evaluated the ability of an RCM to simulate both the mean and extreme precipitation over Spain.

When studying future regional climate changes there are many different sources of uncertainty. Here these sources of uncertainty are broken down into three main sources (ignoring internal variability), a different but similar way to categorise these sources of uncertainty can be found in Foley (2010). The first source, and one of the largest unknowns, is the future emissions of greenhouse gases. Since this is dependent on human activities and policy actions, the future evolution of greenhouse gas emissions is presented as a series of possible emission scenarios or projections. These scenarios are then used in GCM simulations to study the impact on climate. At the climate model grid scale we do not solve the known fundamental physical laws controlling the climate system but approximate them which is the second source of uncertainty. This uncertainty is embodied in the GCM model physics and numerical structure. The last main source of uncertainty is the downscaling method itself. In the case of RCMs this includes the model physics and structure similar to issues associated with GCMs. In combination these sources of uncertainty provide a limit to the confidence that can be placed in any particular projection of future regional climate.

Quantifying this uncertainty is done by creating a collection, or ensemble, of climate simulations that sample various parts of the uncertainty described above. Emission scenario uncertainty is addressed by running simulations from more than one scenario. To quantify the uncertainty associated with GCMs an ensemble of many GCMs should be used and similarly for RCMs (or dynamical downscaling) many RCMs should also be used. Ideally these GCMs and RCMs would be independent of each other ensuring they are sampling from different parts of the plausible future climate space. Once an ensemble which samples these uncertainties has been established there are multiple methods for combining the information to establish a comprehensive future climate change prediction.

\section{THE NARCLIM PROJECT}

The NARCliM ensemble has been designed to produce 12 regional climate model projections (Evans et al., 2014). Twelve RCM runs were selected as a minimum number of runs to improve the probability of capturing the range of possible future climates. The process of developing the 12 projections first includes the selection of the GCMs that will be downscaled. The project uses four independent GCMs to provide the boundary conditions for three RCM simulations each, for a total of 12 projections. The GCM selection process was based on a combined evaluation of GCM performance in simulating recent climate for this region, contain independent model errors (Evans et al., 2013) and that provide an ability to span the range of future climate change projections. The three RCMs were similarly chosen based on model performance (Ji et al., 2014) and error independence. Three 20 year simulations were performed with each of the 12 GCM/RCM combinations, for the present day (1990-2009) and two future periods, 2020-2039 and 2060-2079. In addition to the GCM driven simulations the RCMs used boundary conditions from reanalysis to produce long (60year) historical simulations. The NARCliM domain is shown in Figure 1. The large outer domain is modelled using $\sim 50 \mathrm{~km}$ resolution while the inner high resolution domain is modelled using $\sim 10 \mathrm{~km}$ resolution. The resolution is chosen in order to capture important local land-atmosphere coupling feedbacks (Evans et al. 2011). The RCMs chosen are three different configurations of the Weather Research and Forecasting (WRF) model that has been shown to perform well over the region across a range of time scales (Evans et al. 2012; Evans and Westra, 2012; Evans and McCabe, 2013). 


\section{SON pracc seasonal index \& region correlation ( $5 \%$ sig.)}
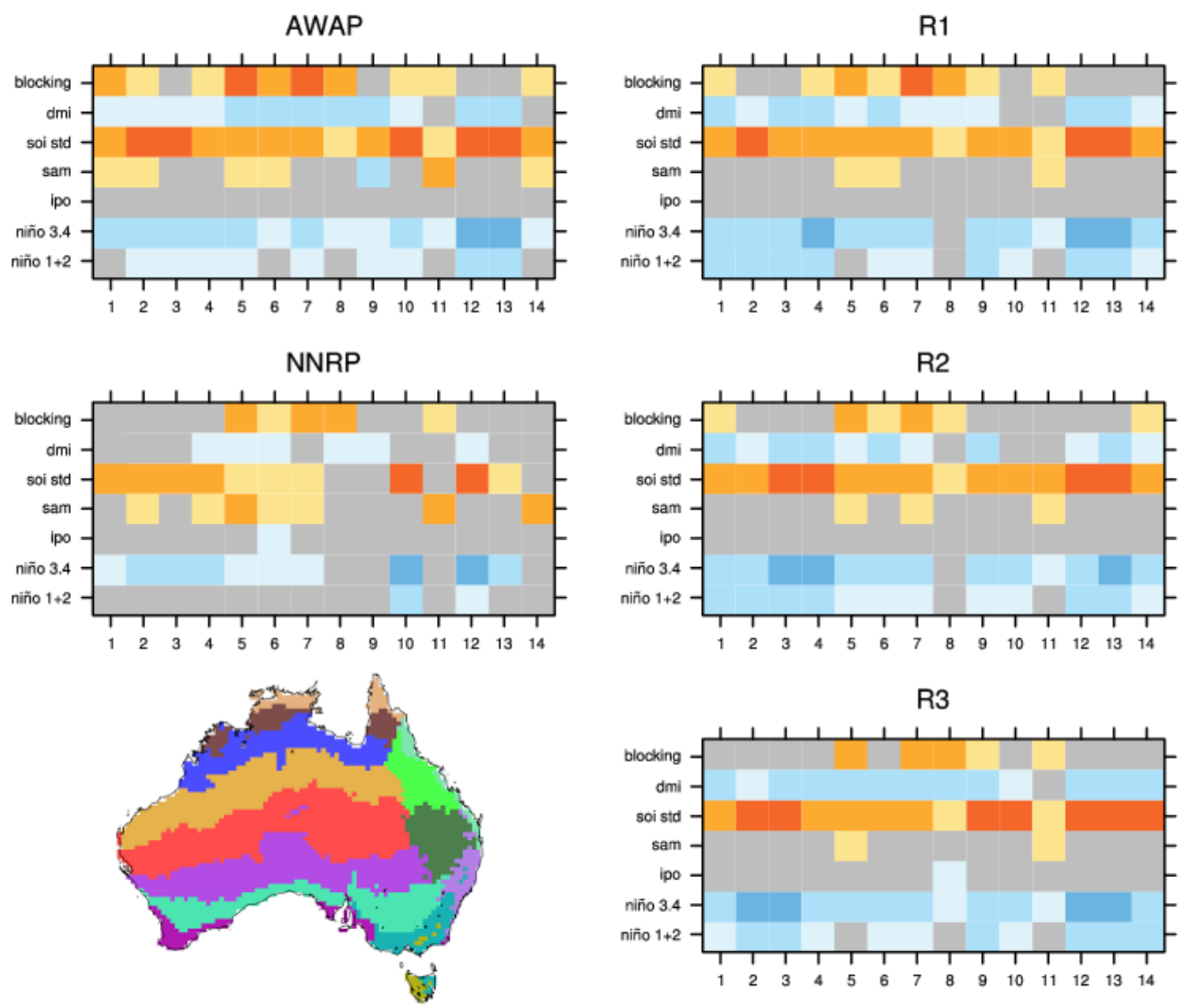

R3

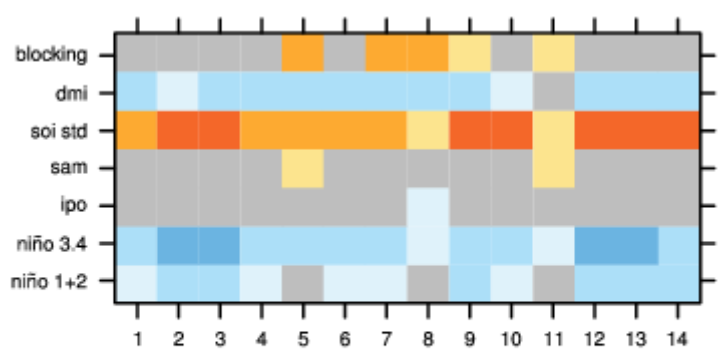

regions

\begin{tabular}{lll|l|l|l|l|l|l|l|l|l|l|l|l|l}
2 & 3 & 4 & 5 & 6 & 7 & 8 & 9 & 10 & 11 & 12 & 13 & 14
\end{tabular}

correlation

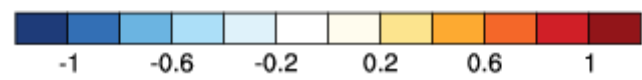

Figure 2. September-October-November regional spatial mean time-series correlation with different climatological indices for precipitation (pracc) in observations (AWAP), NNRP reanalysis and three regional climate model configurations using NNRP as input. Only correlation values above the $95 \%$ confidence level are plotted. Blocking $=$ atmospheric blocking in the Tasman Sea, DMI $=$ Dipole Mode Index, SOI STD = Southern Oscillation Index standard deviation, SAM = Southern Annular Mode, IPO = Inter-decadal Pacific Oscillation, NINO3.4 = sea surface temperature in the 3.4 box in the Pacific (a measure of the El Nino Southern Oscillation. NINO1+2 = as for NINO3.4 but in the 1 and 2 boxes

\section{RESULTS}

The RCMs have been investigated for their ability to reproduce observed relationships between local climate variables and large scale oceanic modes. Figure 2 shows a summary of the model ability to capture the correlation between precipitation in various regions and large scale mode indices averaged during September-October-November (SON). The observed correlations are given by the Australian Water Availability Project (AWAP - Jones et al., 2009) data in the top left panel which provides the pattern of correlations that the models are attempting to simulate. The NCEP/NCAR Reanalysis Project 1 (NNRP Kalnay et al., 1996) data correlations are shown in the centre left panel. NNRP provides the boundary conditions used to drive the three regional models R1, R2 and R3.

Figure 2 shows that NNRP underestimates the correlations of rainfall with the Indian Ocean Dipole (DMI) while the regional models are better able to capture the strength and spatial extent of this correlations. NNRP also underestimates the correlation with blocking, with both R2 and R3 producing similar underestimates, but 
R1 better able to capture the strength and spatial extent. The strongest correlations are found with the tropical Pacific Ocean indexes SOI and Nino 3.4. Again it can be seen that NNRP underestimates the strength and spatial extent of these correlations while the regional models do a much better job. In particular NNRP fails to capture these correlations in regions 8,9,11 and 14 which all cover parts of southeast Australia. It is clear that the RCMs do a generally better job at capturing the pattern of correlations compared to the driving reanalysis though for each model cases of poorer performance can be found. Similar analysis across all seasons confirms the general improvement achieved by the RCMs.

Investigating the biases of the climate model ensembles reveals a spread amongst the models which reflects to a large extent the spread in the GCM CMIP3 ensemble but also includes variations due to the three different RCMs. Figure 3 shows the biases in precipitation in the host GCM and the RCM ensembles. While some of the wet bias found in the RCM ensemble is inherited from the host GCM ensemble, some aspects such as the coastal dry bias in all seasons in the GCM ensemble is not present in the RCM ensemble. This difference is very evident in spring where the GCMs have dry biases for large parts of regions 7, 11 and 14. We can see that in the eastern portion of region 7 the RCM ensemble also produces a dry bias, while for large parts of regions 11 and 14 the RCM ensemble produces a wet bias. Given the relative correlations shown in figure 2, the large differences in biases seen here correspond to regions where different strengths of tropical Pacific Ocean teleconnections are found between the RCMs and driving model. Correlations with blocking and SAM are reasonably similar in the RCM simulations and improve upon NNRP, with some regional exceptions.

\section{CONCLUSIONS}

While the NARCliM RCMs do not exactly reproduce the observed teleconnections with large-scale climate modes seen in observations, they do reproduce the overall structure and improve on the driving global model (NNRP in this case). Here we have shown that the RCMs improve on the correlations found using the NNRP reanalysis even though the RCMs do not assimilate data within the domain while the reanalysis does.

The present day precipitation biases are quite similar for the NARCliM RCM ensemble and the driving host GCM ensemble with some exceptions. The largest difference occurs in Spring when an extensive dry bias in the host GCMs is not matched by the RCMs in regions where they have significant correlations with tropical Pacific Ocean climate mode indices that the driving reanalysis did not. This suggests that differing simulations of teleconnections between host model and RCM may affect the overall climate produced. This is a work in progress and further work is needed to investigate the host GCM produced climate modes and teleconnections. And to understand whether the differences found between the NNRP simulated teleconnections and the RCM (driven by NNRP) teleconnections can be generalized to other global scale host models.

\section{ACKNOWLEDGMENTS}

The NARCliM project is funded and managed by the NSW Office of Environment and Heritage. This research was undertaken with the assistance of resources provided at the NCI National Facility systems at the Australian National University through the National Computational Merit Allocation Scheme supported by the Australian Government.

\section{REFERENCES}

Argüeso, D., J.M. Hidalgo-Muñoz, S.R. Gámiz-Fortis, M.J. Esteban-Parra, Y. Castro-Díez(2012), Evaluation of WRF Mean and Extreme Precipitation over Spain: Present Climate (1970-99), J. Climate. $254883-$ 4897.

Christensen, J., and O. Christensen (2007), A summary of the PRUDENCE model projections of changes in European climate by the end of this century, Climatic Change, 81, 7-30, doi:10.1007/s10584-006-9210-7.

Deque, M. et al. (2005), Global high resolution versus Limited Area Model climate change projections over Europe: quantifying confidence level from PRUDENCE results, Climate Dynamics, 25(6), 653-670, doi:10.1007/s00382-005-0052-1.

Evans, J.P. (2009), Global warming impact on the dominant precipitation processes in the Middle East, Theoretical and Applied Climatology, 99(3), 389-402.

Evans, J.P. (2009a), 21st century climate change in the Middle East, Climatic Change, 92(3-4), 417-432. 
Evans et al., NARCliM model performance including teleconnections with climate modes

Evans, J.P. (2010) Global warming impact on the dominant precipitation processes in the Middle East. Theoretical and Applied Climatology, 99 (3-4), 389-402.

Evans, J.P, M. Ekström, and F. Ji (2012) Evaluating the performance of a WRF physics ensemble over South-East Australia. Climate Dynamics, 39(6), 1241-1258, DOI 10.1007/s00382-011-1244-5.

Evans, J. P., F. Ji, C. Lee, P. Smith, D. Argüeso, and L. Fita (2014) Design of a regional climate modelling projection ensemble experiment - NARCliM. Geosci. Model Dev., 7, 621-629, doi:10.5194/gmd-7-6212014.

Evans, J. P., F. Ji, G. Abramowitz, and M. Ekström (2013) Optimally choosing small ensemble members to produce robust climate simulations. Environ. Res. Lett., 8, 044050, doi:10.1088/1748-9326/8/4/044050.

Evans, J.P., and M. F. McCabe (2010), Regional climate simulation over Australia's Murray-Darling basin: A multitemporal assessment, J. Geophys. Res., 115(D14114), doi:10.1029/2010JD013816.

Evans, J.P. and M.F. McCabe (2013) Model resolution impact on regional climate and climate change using WRF over south-east Australia. Climate Research, 56(2), 131-145, doi:10.3354/cr01151.

Evans, J.P., R.J. Oglesby and W.M. Lapenta (2005), Time series analysis of regional climate model performance, Journal of Geophysical Research D: Atmospheres, 110(4), 1-23.

Evans, J.P., A.J. Pitman and F.T. Cruz (2011) Coupled atmospheric and land surface dynamics over South East Australia: A review, analysis and identification of future research priorities. International Journal of Climatology, 31, 1758-1772.

Evans, J.P., R.B. Smith and R.J. Oglesby (2004), Middle East climate simulation and dominant precipitation processes, International Journal of Climatology, 24(13), 1671-1694.

Evans, J.P. and S. Westra (2012) Investigating the Mechanisms of Diurnal Rainfall Variability Using a Regional Climate Model, Journal of Climate, 25, 7232-7247, doi:10.1175/JCLI-D-11-00616.1.

Foley, A. (2010), Uncertainty in regional climate modelling: A review, Progress in Physical Geography, 34(5), 647-670, doi:10.1177/0309133310375654.

Fowler H.J., S. Blenkinsop, C. Tebaldi (2007) Linking climate change modelling to impacts studies: Recent advances in downscaling techniques for hydrological modelling. International Journal of Climatology 27:1547-1578.

IPCC (2007), Climate Change 2007: The Physical Science Basis, edited by S. Solomon, D. Qin, M. Manning, Z. Chen, M. Marquis, K.B. Averyt, M. Tignor, H.L. Miller, Cambridge University Press, Cambridge, United Kingdom.

Ji, F., M. Ekström, J. P. Evans, and J. Teng (2014), Evaluating rainfall patterns using physics scheme ensembles from a regional atmospheric model, Theor Appl Climatol, 115(1-2), 297-304, doi:10.1007/s00704-013-0904-2.

Jones, D. A., W. Wang, and R. Fawcett (2009) High-quality spatial climate data-sets for Australia. Australian Meteorological Magazine, 58, 233-248.

Kalnay E, Kanamitsu M, Kistler R, et al (1996) The NCEP/NCAR 40-year reanalysis project. Bulletin of the American Meteorological Society 77:437-471.

Kendon, E., R. Jones, E. Kjellstrom, and J. Murphy (2010), Using and Designing GCM-RCM Ensemble Regional Climate Projections, Journal of Climate, 23(24), 6485-6503, doi:10.1175/2010JCLI3502.1.

Kostopoulou, E., K. Tolika, I. Tegoulias, C. Giannakopoulos, S. Somot, C. Anagnostopoulou, and P. Maheras (2009), Evaluation of a regional climate model using in situ temperature observations over the Balkan Peninsula, Tellus, Series A: Dynamic Meteorology and Oceanography, 61(3), 357-370.

Mariotti, A., N. Zeng, J. Yoon, V. Artale, A. Navarra, P. Alpert, and L. Li (2008), Mediterranean water cycle changes: transition to drier 21 st century conditions in observations and CMIP3 simulations, Environmental Research Letters, 3(4), doi:10.1088/1748-9326/3/4/044001.

Mearns, L. O., W. J. Gutowski, R. Jones, L.-Y. Leung, S. McGinnis, A. M. B. Nunes, and Y. Qian (2009), A regional climate change assessment program for North America, EOS, 90(36), 311-312.

Meehl, G. A., C. Covey, T. Delworth, M. Latif, B. McAvaney, J. F. B. Mitchell, R. J. Stouffer, and K. E. Taylor (2007), The WCRP CMIP3 multimodel dataset - A new era in climate change research, Bull. Amer. Meteor. Soc., 88(9), 1383-1394.

van der Linden, P., and J. Mitchell (Eds.) (2009), ENSEMBLES: Climate change and its impacts. Summary of research and results from the ENSEMBLES project, Met Office Hadley Centre, Exeter, UK.

Vavrus, S., D. Waliser, A. Schweiger, and J. Francis (2009), Simulations of 20th and 21st century Arctic cloud amount in the global climate models assessed in the IPCC AR4, Climate Dynamics, 33(7-8), 10991115, doi:10.1007/s00382-008-0475-6.

Zaitchik, B.F., J.P. Evans and R.B. Smith (2007a) Regional impact of an elevated heat source: The Zagros plateau of Iran. Journal of Climate, 20: 4133-4146.

Zaitchik, B.F., J.P. Evans, R.A. Geerken and R.B. Smith (2007b) Climate and vegetation in the Middle East: inter-annual variability and drought feedbacks. Journal of Climate, 20: 3924-3941. 